\title{
Evaluation of solar energy on the roofs of livestock houses
}

\author{
Paolo Liberati, Paolo Zappavigna \\ Department of Agricultural and Food Sciences (DISTAL), University of Bologna, Italy
}

\begin{abstract}
There is a great potential for production of thermal and electrical energy by means of solar collectors on farms. To assess in advance the performance of the alternative plant solutions, a computational model for the determination of solar energy absorbed by surfaces with different exposures as a function of latitude, day, orientation and inclination has been created. Its application to roofs of buildings typically used for animal housing is presented; these were mono-pitch, gabled, and shed type roofs. For each building, the annual energy absorption per unit of floor area is calculated by varying orientation and slope of the pitches. For roof surfaces exposed only in one direction (mono-pitch or shed), the orientation is shown to be a dominant factor with respect to the slope in determining the annual energy uptake. The maximum uptake is obtained with exposure to the south and is greater the higher the slope (up to 67.5\%). For gabled roofs, the total uptake is negatively affected by the worse exposed pitch and does not vary significantly, for a given slope, with orientation (up to $2.8 \%$ ). The maximum gain is obtained with the optimal building azimuth $\left(0^{\circ}\right)$ and the highest slope. The shed type, since it is affected by the shade induced by the upper pitch over the lower, cannot reach the level of a mono-pitch roof: $-1.5 \%$ with a slope of $10 \%$ and $-21 \%$ with a slope of $67.5 \%$ with the optimal building azimuth of $90^{\circ}$. However, its performance is slightly higher than the corresponding gabled roof $(+2.5 \%)$, therefore, it could be a convenient alternative if optimally oriented and, above all, if the collectors are installed on the predominantly sunny part of the roof.
\end{abstract}

\section{Introduction}

There is a significant potential for the production of thermal and electrical energy by means of solar collectors installed on the roof of

Correspondence: Paolo Liberati, Department of Agricultural and Food Sciences (DISTAL), University of Bologna, viale G. Fanin 50, 40127 Bologna, Italy. E-mail: paolo.liberati@unibo.it

Key words: animal houses, roofs, solar uptake, estimation, model.

Received for publication: 7 December 2012.

Accepted for publication: 19 February 2012.

(C) Copyright P. Liberati and P. Zappavigna, 2012

Licensee PAGEPress, Italy

Journal of Agricultural Engineering 2012; XLIII:e25

doi:10.4081/jae.2012.e25

This article is distributed under the terms of the Creative Commons Attribution Noncommercial License (by-nc 3.0) which permits any noncommercial use, distribution, and reproduction in any medium, provided the original author(s) and source are credited. farm buildings. This potential is even greater in livestock farming since large building complexes are in use with coverings often in need of replacement, especially if made of asbestos.

In fact, there has been a huge increase in the installation of solar panels and they continue to attract widespread interest (Audfray, 2007; Bruel et al., 2010; Guercini, 2011; Rossi, 2011; Van Caenegem and Pasca, 2009; Van Caenegem et al., 2009). However, no technical references are available to assess in advance the production efficiency of alternative plant solutions in specific farming conditions. The aim of our study was, therefore, to set up a calculation procedure that can estimate the potential for solar energy uptake by surfaces of any exposure and geometry, easily applicable to the roofs of existing buildings or those still on the drawing board. In this paper, the application of the procedure to the roofs of typical animal housing is presented. The results can be used to estimate the energy performance of solar collectors installed on the coverings in a coplanar fashion. Such a plant solution, besides being the most common for its simple design and the most profitable in terms of the availability of national grants, is considered the most suitable for buildings located in rural areas that may damage the quality of the landscape. Furthermore, the main purpose of the present study is to show the potential of the model for use in evaluating different installation modes both on the roofs of the buildings and on the ground.

\section{Materials and methods}

The model calculates the intensity of solar energy absorbed by a unit area (in our application of roof) varying all the factors involved: the location (latitude, day, exposure) and the construction characteristics (size, orientation, roof typology and slope). It is based, as a first step, on the online programme developed by the Joint Research Centre Institute for Energy and Transport of the European Commission (2012) that estimates solar energy catchable by a given area with any exposure and inclination, through two different types of climate data: i) Photovoltaic Geographical Information System (PVGIS)-classic, which uses interpolated data taken from ground stations (to determine the climate pattern of a specific location when the station is not locally available); ii) PVGIS-satellite application facility (PVGIS-SAF), which uses climate data reconstructed from satellite measurements.

The above programme has been preferred over another based on climate data referring to the Ente Nazionale Italiano di Unificazione (UNI) regulation no. 10349 (UNI, 1994), as being more suitable to simulate all possible combinations of orientation and slope. In reality, the choice of the reference database can give rise to significant differences in the values of solar radiation. For example, the PVGIS-classic database, used in the present study, gives lower values than the PVGISSAF database and the UNI regulation no. 10349 (UNI, 1994) (a difference of from $10 \%$ to approximately 15\%) depending on the slope and orientation. However, given the comparative nature of our study, this fact is irrelevant for the purposes of this paper. So, using the PVGIS software, unitary uptake $\left(E_{n}, \mathrm{kWh} \mathrm{m}^{-2}\right)$ has been calculated for a surface considering six different slopes $(10 \%, 20 \%, 30 \%, 40 \%, 50 \%$ and 
$67.5 \%$, corresponding to inclinations of $5.7^{\circ}, 11.3^{\circ}, 16.7^{\circ}, 21.8^{\circ}, 26.6^{\circ}$ and $34.0^{\circ}$, respectively), and eight azimuths referred to North $\left(0^{\circ}=\mathrm{N}\right.$, $45^{\circ}=\mathrm{NE}, 90^{\circ}=\mathrm{E}, 135^{\circ}=\mathrm{SE}, 180^{\circ}=\mathrm{S}, 225^{\circ}=\mathrm{SW}, 270^{\circ}=\mathrm{W}$, and $\left.315^{\circ}=\mathrm{NW}\right)$.

The slope of $67.5 \%$ is taken as the limit because it optimises the annual energy uptake in our latitudes (Reggio Emilia, north-west Italy) and is likely to provide an immediate reference for non-coplanar installations. The slope of $10 \%$ is the minimum slope used for roofs covered with metal or fibre cement sheeting. The slope of $30 \%$ is common for roofs covered with tiles.

The latitude has little effect on the optimum angle of inclination as regards the annual absorption. For example, moving from a latitude of $37^{\circ} 30^{\prime} \mathrm{N}$ (Catania, Sicily, Italy; Seville, Spain, $37^{\circ} 23^{\prime}$ ) to $44^{\circ} 41^{\prime} \mathrm{N}$ (Reggio Emilia, north-west Italy; Bordeaux, France, $44^{\circ} 50^{\prime}$ ), the optimum angle increases only by three degrees. In reality, there is no single optimum value of inclination for a given latitude. For example, in the case of Reggio Emilia, all inclinations ranging from $30^{\circ}$ to $42^{\circ}$ allow us to obtain the maximum possible annual absorption. In fact, increasing the inclination increases the absorption in winter at the expense of the absorption in summer. At lower latitudes, absorption is similar but the range of inclination that maximises the annual absorption is reduced (e.g. for Catania, the range is $28^{\circ}-36^{\circ}$ ).

The next step was to calculate the amount of solar radiation over the entire roof by varying the building orientation and the roof slope in relation to three types of buildings suitable for livestock production: with a mono-pitch roof (Figure 1A, area $8 \times 50 \mathrm{~m}$ ); with a gable roof (Figure 1B, 16×50 m); with a shed roof (Figure 1C, 16×50 m).

The building dimensions refer to real cases: Figure 1A refers to a structure with a single span with simple flat beams (mainly used for pig housing); Figure 1B refers to a structure with a single span with a gabled beam (used for all livestock housing); Figure $1 \mathrm{C}$ refers to a structure with an intermediate pillar (mainly used for dairy cow housing). Differences in size of floor area (and consequently in the size of the roof) do not affect our comparison since it is carried out with reference to the unit area of the horizontal projection (floor surface) and not the surface of the roof. The building orientation is referred to the azimuth of the building axis that is the exposure of the P1P2 wall as in Figure 1, where the three building types are reported facing North (azimuth $=0^{\circ}$ ). All graphs refer to the building orientation; therefore, the exposure of the pitch (pitches) for a given building orientation can be calculated from Figure 1. In the case of buildings with a shed roof, our study took into account the shadow cast by one pitch above the other. Figure 2 shows the case of a north-facing building over $4 \mathrm{~h}$ of the morning of $30^{\text {th }}$ August $(6,7,8$ and $10 \mathrm{am}$; location Reggio Emilia, north-west Italy). For this orientation, there is no longer any shade above the roof after noon. The building orientation, the roof slope and the sun elevation all have a different influence on the shading dynamics, as explained below. In particular, for each day of the year, an index of relative uptake quantifying the fraction of energy captured from the shaded pitch on the non-shaded throughout the day has been calculated with the following formula:

$$
I_{R U}(d)=\frac{\iint S_{s}(t) \cdot R_{d}(t) \cdot d t}{S_{f} \int R_{d}(t) \cdot d t}
$$

where:

$I_{R U}$ is the index of relative uptake (dimensionless);

$d$ is the day of the year;

$S_{s}$ is the area of the surface of the pitch not in shade at time $t\left(\mathrm{~m}^{2}\right)$;

$S_{f}$ is the total area of the pitch $\left(\mathrm{m}^{2}\right)$;

$R_{d}$ is the direct radiation $\left(\mathrm{W} \mathrm{m}^{-2}\right)$;

$t$ is the time (s).
Once the daily energy captured from the unshaded pitch is known ( $E_{n}$, as obtained in the first step of the calculation procedure), the energy of the partially shaded pitch $\left(E_{s}\right)$ can be calculated as:

$$
E_{s}=I_{R U} \cdot E_{n}
$$

The calculation of the relative uptake index is possible thanks to a second dynamic and 3-dimensional model described by Liberati and Zappavigna (2007) that allows indoor climatic conditions to be estimated according to the various energy inputs, both internal and external.

In our case, from the last model we use only the procedure to calculate the boundary conditions of the surface coverage according to:

$$
\left.\lambda_{o} \frac{\partial T_{s o}}{\partial x_{s o}}\right|_{x=0}=P_{s}+\gamma_{o}\left(T_{o}-T_{s o}\right)+P_{R S}
$$

where:

$T_{s o}$ is roof surface temperature $(\mathrm{K})$;

$\lambda_{0}$ is specific thermal conductivity of the outsider layer $\left(\mathrm{W} \mathrm{m}^{-1} \mathrm{~K}^{-1}\right)$;

$P_{s}$ is solar contribution, both direct and diffuse radiation $\left(\mathrm{W} \mathrm{m}^{-2}\right)$;

$\gamma_{o}$ is outside convective coefficient $\left(\mathrm{W} \mathrm{m}^{-2} \mathrm{~K}^{-1}\right)$;

$T_{o}$ is outside air temperature $(\mathrm{K})$;

$P_{R S}$ is radiative heat exchanged between roof surface and the sky $\left(\mathrm{W} \mathrm{m}^{-2}\right)$.

In order to calculate the value of direct radiation included in $P_{s}$ the solar vector at each step of the simulation has been determined according to the procedure proposed by Blanco-Muriel et al. (2001). To evaluate the sunny surface area $\left(S_{s}\right)$ of the shaded pitch, the development of a supplementary code (shading module) integrated in the above model was preferred to using a commercial software package, so that the $I_{R U}$
A)

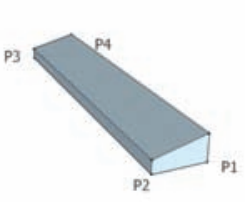

B)

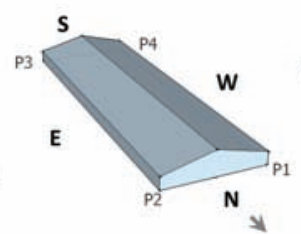

C)

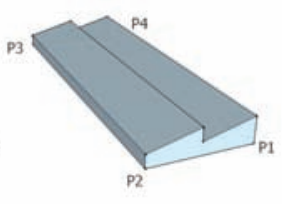

Figure 1. Buildings with (A) mono-pitch, (B) gabled, and (C) shed roofs. The orientation of the building refers to the azimuth of the P1P2 wall $\left(\mathrm{N}=0^{\circ}, \mathrm{E}=90^{\circ}, \mathrm{S}=180^{\circ}, \mathrm{W}=270^{\circ}\right)$.

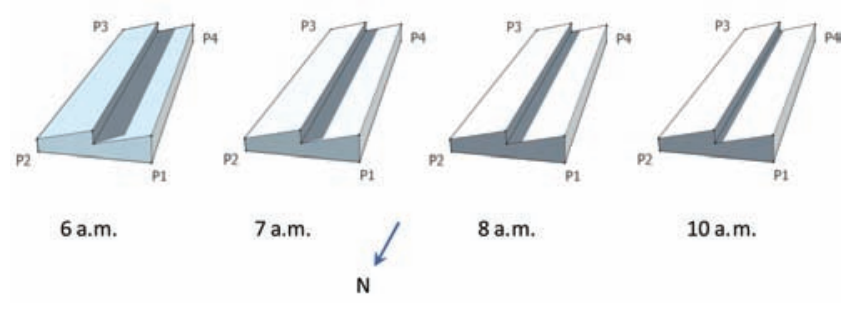

Figure 2. Building with shed type roof. The darker surface of the roof represents the shadow projected from the P2P3 pitch over the P1P4 as a function of the sun position. A case of a north-facing building for $4 \mathrm{~h}$ on the morning of August 30th $(6,7,8$ and $10 \mathrm{a} . \mathrm{m}$.). For this orientation, there is no longer any shading of the roof after noon (location: Reggio Emilia, north-west Italy). 
indexes could be calculated automatically.

The shading module projects the sun's rays on the incident surface so that an opaque object encountered in the ray path is drawn as a shadow.

In particular, starting from the direction cosines of the inclination vector of the sun's rays for a given hour of the day, and the characteristic points (vertices) of the sunny pitch which determine the shadow dropped on the adjacent pitch (AP), the parametric equations of the straight lines projecting these points on the surface AP are identified. Subsequently, the Cartesian equation of the $\pi$ plane representing the surface AP (through three of its characteristic points) for a given orientation of the building and a given slope of the roof is defined. The calculation proceeds with the determination of the coordinates of the shadow points identified by the intersections of the $\pi$ plane with the projection lines; the coordinates are obtained by solving the system of the plane-line equations in the 3D space. Once the projecting points in the shaded pitch are known, we can calculate the sunny area $S_{s}$ by subtracting the shaded area from the $S_{f}$ area.

To ensure comparability of the different types of roof (differentiated by size, shape and slope of the roofing pitches), the energy uptake per square meter of floor area is the most representative variable, since it best expresses the theoretical energy obtainable from each type of building (and consequently by solar panels installed in a coplanar fashion on the entire roof).

It should be noted that, in this calculated variable, the slope has a very important dual role, producing, as it grows, both an increase in the density of the solar radiation uptake (at least up to approximately $67.5 \%$ of inclination) and in the ratio of the roofing area to the floor area. To better illustrate this mechanism, we compared the potential uptake related both to the roof area and the building floor area (Figure 3) only for the mono-pitch roof type (Figure 1A).
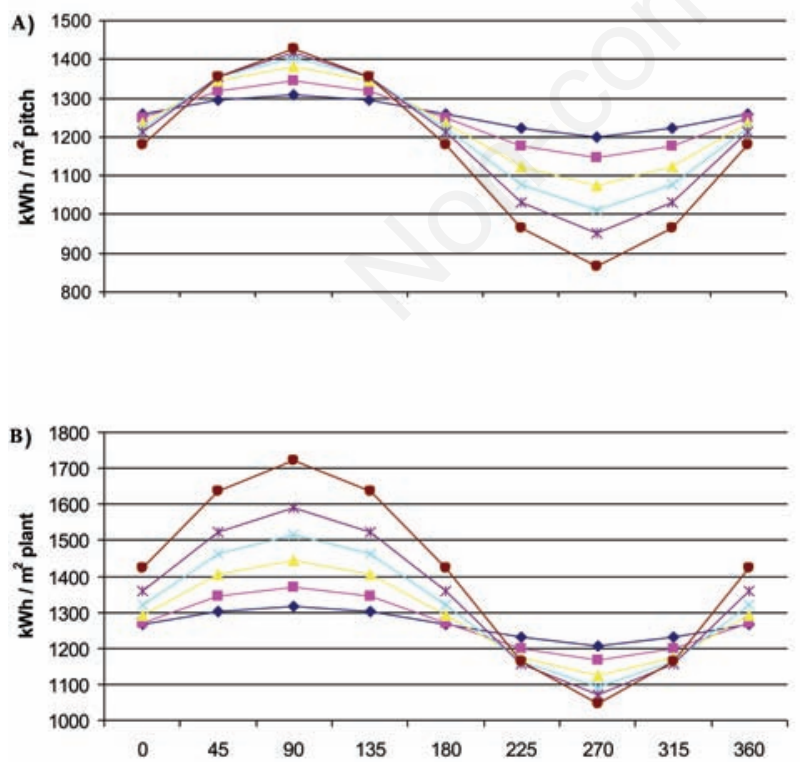

Figure 3. Annual energy uptake for a mono-pitch building as a function of the building orientation and roof slope $\left(\mathrm{kWh} \mathrm{m}^{-2}\right)$ : (A) per $\mathrm{m}^{2}$ of the roof pitch area; (B) per $\mathrm{m}^{2}$ of the floor area. At these latitudes, the slope of $67.5 \%$ optimises the annual uptake for a south-facing pitch (in principle, this slope can be considered to be optimal for all locations in Italy).

\section{Results and discussion}

Results refer to the latitude of $44^{\circ} 41^{\prime} 46^{\prime \prime} \mathrm{N}$, corresponding to the zone of Reggio Emilia, (north-west Italy) and relate to the potential energy uptake on an annual, and in some cases seasonal, basis. Moreover, only for the shed type, the rate of relative uptake index $\left(I_{R U}\right)$ has been calculated for a representative day of each season. As stated above, the orientation (azimuth) of the building refers to the exposure of the wall P1P2 (Figure 1).

\section{Mono-pitch buildings}

It is well known that at these latitudes the maximum annual energy uptake is obtained with a surface inclination of approximately $34^{\circ}$ (corresponding to a slope of 67.5\%) and exposure to South (which corresponds to an azimuth of $90^{\circ}$ for the building of Figure 1A). As can be seen in Figure $3 \mathrm{~A}$, with favourable exposures the uptake per square meter of roofing area increases with the slope, but the gain decreases, becoming negligible over $40 \%$ and practically null with azimuth values around $20^{\circ}$ and $150^{\circ}$. Between these two limits, the effect of the slope is reversed and the maximum uptake values are obtained with a nearly horizontal disposition of the surface. The results change considerably if, instead, we look at the potential uptake related to the square meter of plan (Figure 3B) because, as stated above, the slope plays a double action by significantly boosting the performance in the field of more favourable azimuths. The opposite occurs with less favourable exposure fields (i.e. for azimuths between approximately $200^{\circ}$ and $330^{\circ}$ ), moreover, much more limited compared to the previous diagram (Figure $3 \mathrm{~A}$ ). In essence, the comparison shows us the two examined variables express different kinds of uptake and are more or less adequate to make estimates of energy yield depending on the installation of the collectors (coplanar or otherwise). Continuing to consider the uptake referred to the floor area, we estimated the seasonal performance obtainable with two roof slopes that delimit a range of current
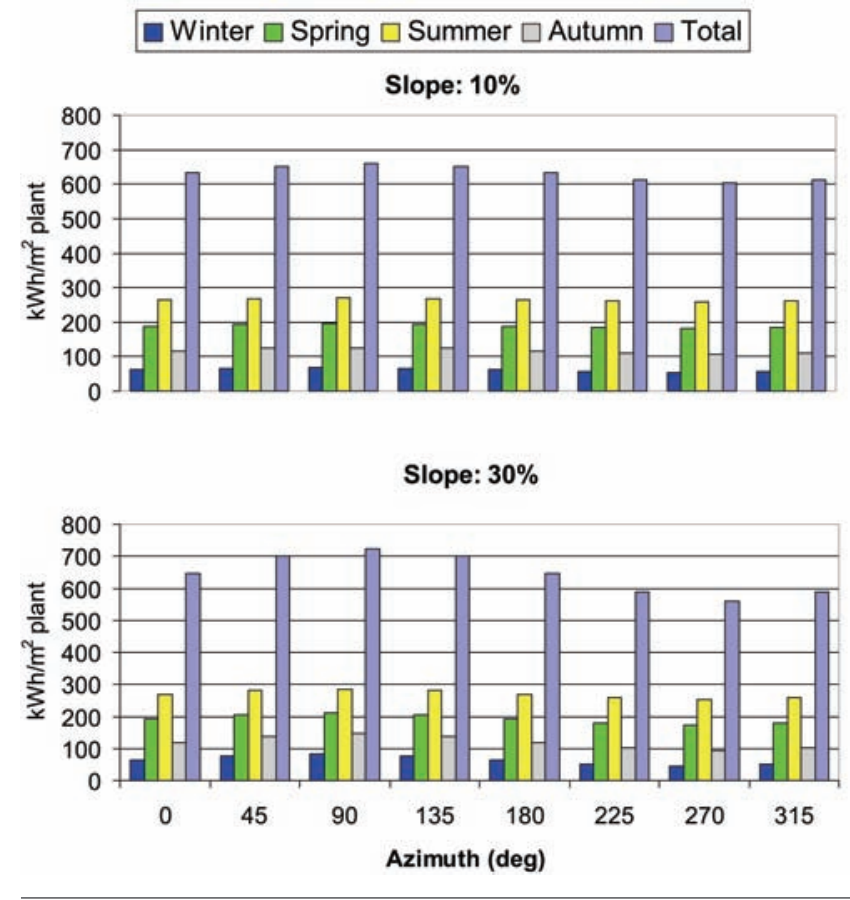

Figure 4. Seasonal pattern of energy uptake ( $\mathrm{kWh} \mathrm{m}^{-2}$ floor plan) for a mono-pitch building for eight orientations and two roof slopes. 
use in animal housing (Figure 4). It should be noted that, in this case, with an optimal azimuth (around $90^{\circ}$ ), the maximum slope provides the best performance in all seasons ( $+9 \%$ between the two considered cases). On the contrary, for the worst orientation $\left(270^{\circ}\right)$, it is the minimum slope that offers the best performance $(+8 \%)$, mainly due to the higher uptake attainable in autumn $(+17 \%)$ and winter $(+26 \%)$.

\section{Buildings with gabled roof}

Unlike the previous case, the energy catchable by a gabled roof per unit of covered area does not vary significantly, for a given slope, with the orientation. In fact the maximum deviation is $2.8 \%$ with the highest slope (Figure 5 , limited to only two quadrants by symmetry), and tends

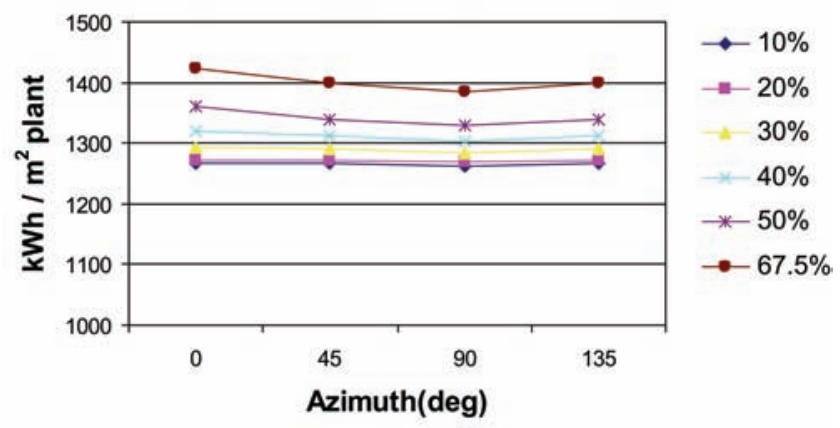

Figure 5. Annual energy uptake for a gabled roof as a function of the building orientation and roof slope, considering the contribution of both pitches ( $\mathrm{kWh} \mathrm{m}^{-2}$ floor area).

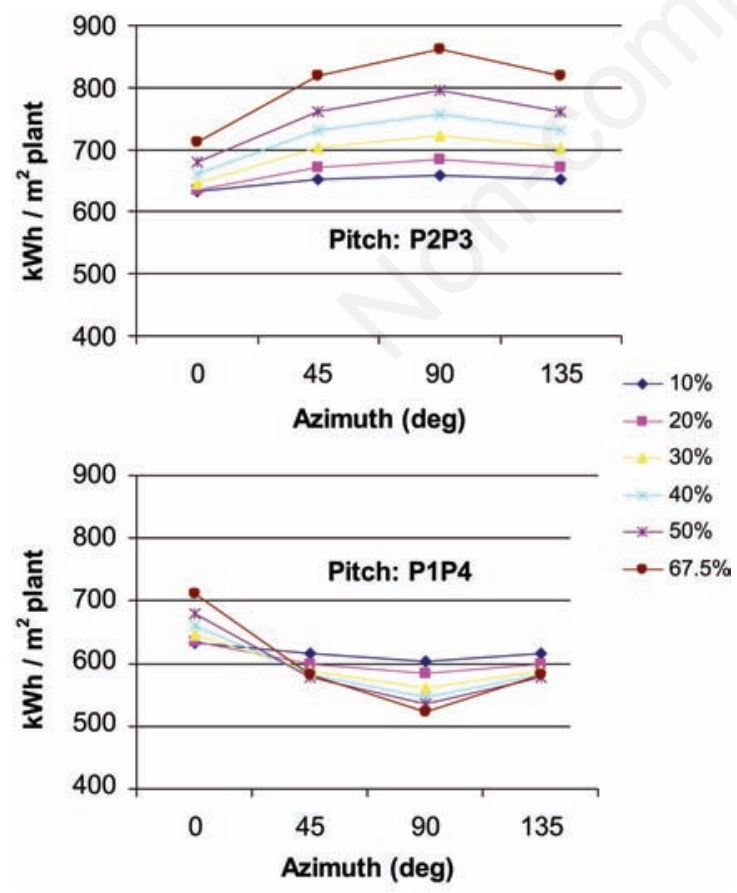

Figure 6. Patterns of the annual energy uptake for each pitch of a gabled roof as a function of the building orientation and roof slope ( $k$ Wh m ${ }^{-2}$ floor area). to virtually zero approaching the horizontal plane. This fact is explained by observing the behaviour of each pitch for different azimuths (Figure 6) from which one can see that a performance improvement of one pitch corresponds to a worsening of the adjacent pitch. For the same reason, even if the maximum overall performance is achieved again with the highest slope (and with azimuth equal to zero, Figure 5), the gain obtained passing from a slope of $10 \%$ to $67.5 \%$ is just $13 \%$. A comparison with the previous case shows that the maximum uptake of a gabled roof is significantly lower, per unit of floor area, than a mono-pitch roof (whatever the slope) for the simple reason that the maximum performance cannot be achieved by both pitches.

However, the performance difference decreases with the slope (from $20 \%$ to slightly more than $2 \%$ ) and is around $5 \%$ for the common slopes

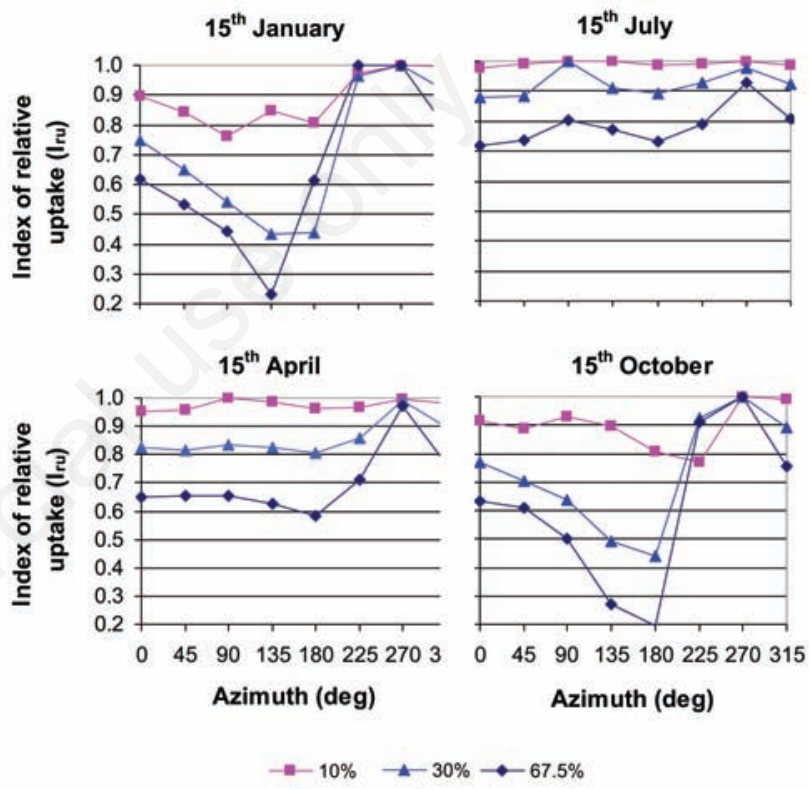

Figure 7. Performance of the index of relative uptake $\left(I_{R U}\right)$ regarding a building with a shed roof, for four days (one per season), three slopes and eight orientations. There is no shading with $\mathrm{I}_{\mathrm{RU}}=\mathbf{1}$.

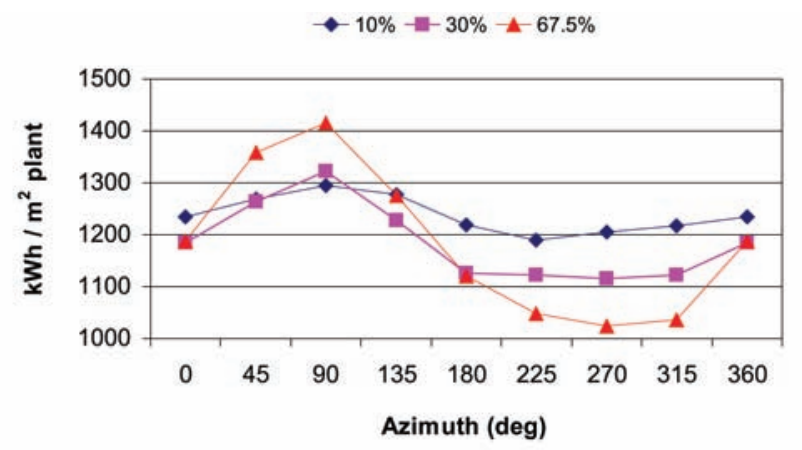

Figure 8. Annual energy uptake for a building with a shed roof as a function of the building orientation and the roof slope, considering the contribution of both pitches ( $\mathrm{kW} \mathrm{m}^{-2}$ of floor area). 
of many pre-fabricated structures (10\%-15\%). For buildings with azimuth close to zero, in which the two pitches have an equivalent uptake thus allowing double absorption, the uptake per square meter of floor area is approximately equal to that of a mono-pitch building with the same slope and orientation.

\section{Buildings with shed roof}

Compared to the gabled roof, the shed roof offers, for buildings of the same size, a larger surface with optimal exposure to the sun that behaves substantially in the same way as the mono-pitch roof, except for the limitation due to the shading induced by the upper pitch over the lower. The shading effect varies clearly with the slope, as shown in Figure 7 where, as an example, the indices of relative uptake $\left(I_{R U}\right)$ of the shaded pitch are reported for four days representative of each season and for three different slopes. From the graph it appears that the biggest loss due to shading is seen with the highest slope, for all orientations and for each season, and is never totally null.

For this reason, the maximum annual energy uptake per square meter of floor area (Figure 8), even with the optimal azimuth of $90^{\circ}$, may not reach the level of a mono-pitch roof (-1.5\% with a slope of $10 \%$, $-9 \%$ with a slope of $30 \%,-17.9 \%$ with a slope of $67.5 \%)$, although still higher, albeit slightly, than the corresponding gabled roof $(+2.5 \%$ with a slope of $30 \%$ ).

The shading effect increases the higher the slope, and in autumn and winter is greater with azimuths between $135^{\circ}$ and $180^{\circ}$, while in spring and summer the azimuth has no effect.

The advantage of this type of roof compared to a gabled one, from the point of view of efficiency of the solar collectors, is much greater as the highest overall uptake can be obtained with a lower surface of the panels (i.e. excluding the portion of the roof which remains for more time in the shade); a solution that can be easily optimised thanks to our model. As with the mono-pitch roof, the lowest uptake occurs with azimuth around $270^{\circ}$ (the worse the greater the slope) and the greater slopes optimise the uptake only if the azimuth is around $90^{\circ}$; instead, with azimuths around $135^{\circ}$ the effect of the slope is reversed.

\section{Conclusions}

The calculation model presented here allows the solar energy uptake of roofs with any shape and orientation to be evaluated. It can, therefore, be a useful tool to optimise the installation of solar collectors on farm buildings, the convenience of which can vary greatly from case to case. The application of the model on some typical animal housing carried out in this study gives some general guidelines. For roofs with pitches exposed in one direction (mono-pitch or shed), the orientation is the dominant factor. The slope has an important and controversial role to maximise uptake: with favourable orientation, its increase has a positive effect whilst with unfavourable orientation it has a negative effect. For this reason, in order to optimise the performance, a tool allowing an overall assessment of the combined effect of orientation and slope is essential. For roofs with two opposite slopes (gabled roofs), the overall performance is penalised by the worse exposed pitch. But since it depends very much on the slope and very little on the orientation, it is possible to obtain a fairly good yield for any orientation. However, the exploitation of solar panels (thermal or photovoltaic) is much more effective if only the better exposed pitch is used. In these cases the mono-pitch is exploited. For double pitch roofs, the shed type can be a more convenient alternative if optimally oriented and, most importantly, excluding the collectors from the part of the roof usually in shadow. In addition to these indications, the calculation model could well be used together with procedures aimed at an economic evaluation of energy production (depending on the panel technology, the type of government grants available and the amount of energy used on the farm), and with models predicting the climatic conditions inside the buildings.

\section{References}

Audfray J.L. 2007. Les capteurs solaires thermiques. Fiche no. D51. Chambre d'Agriculture de la Loire, Paris, France.

Blanco-Muriel M., Alarcón-Padilla D.C., López-Mortalla T., Chur L.M. 2001. Computing the Solar Vector. Sol. Energy. 70:431-41.

Bruel A., Coutant S., Mary J., Menard J.l., Pilet J.M., Pineteau S., Prud'homme J.F., Rocheteau P. 2010. Reussir son bâtiment agricole avec du photovoltaïque. Chambre d'Agriculture de la Loire, Paris, France.

Guercini S. 2011. In stalla anche l'energia è un fattore di produzione. Informatore Zootecnico. 2:30-4.

European Commission (Joint Research Center). 2012. Photovoltaic Geographical Information System (PVGIS). Available from: http://re.jrc.ec.europa.eu/pvgis/apps4/pvest.php\#

Liberati P., Zappavigna P. 2007. A dynamic computer model for optimization of the internal climate in swine housing design. T. ASABE. 50:2179-188.

Rossi P. 2011. Fotovoltaico: per le aziende zootecniche una buona opportunità. Agricoltura. 39:55-6.

UNI (Ente Nazionale Italiano di Unificazione). 1994. [Heating and cooling of buildings - Climatic data]. UNI 10349:1994. Ente Nazionale Italiano di Unificazione, Roma, Italy. Available from: http://store.uni.com/magento-1.4.0.1/index.php/uni-103491994.html?josso_back_to=http://store.uni.com/josso-securitycheck.php\&josso_cmd=login_optional\&josso_partnerapp_host=st ore.uni.com

Van Caenegem L., Bollhalder H., Dörfler R., Gazzarin C., Nydegger F., Ott H.R., Pasca A., Schmidlin A. 2009. Exploitation thermique des installations photovoltaïques intégréès dans la toiture. Tänikon ART, Tänikon, Switzerland.

Van Caenegem L., Pasca A. 2009. Combined electrical and thermal use of photovoltaic panels. Proc. European Forum Livestock housing for the future, 22-23 October, Lille, France, pp 7-13. 